Document downloaded from:

http://hdl.handle.net/10251/51145

This paper must be cited as:

Cervera Vázquez, J.; Montagud Montalvá, Cl.; Corberán Salvador, JM. (2015). In situ optimization methodology for the water circulation pumps frequency of ground source heat pump systems: Analysis for multistage heat pump units. Energy and Buildings. 88:238-247. doi:10.1016/j.enbuild.2014.12.008.

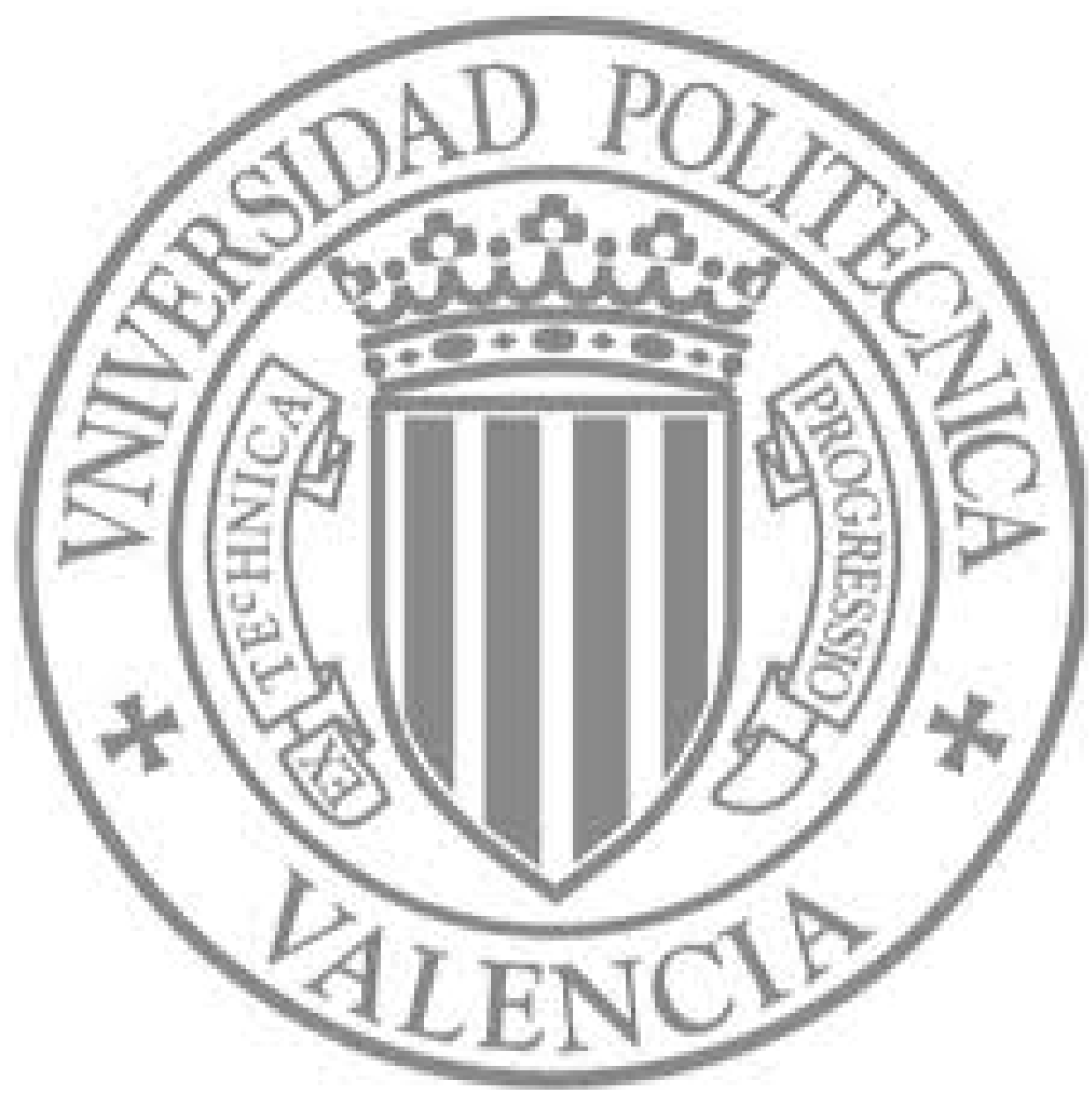

The final publication is available at

http://dx.doi.org/10.1016/j.enbuild.2014.12.008

Copyright Elsevier 


\title{
In situ optimization methodology for the water circulation pumps frequency of ground source heat pump systems: analysis for multistage heat pump units.
}

\author{
J. Cervera-Vázquez , C. Montagud, J. M. Corberán \\ Instituto de Ingeniería Energética, Universitat Politècnica de València, Camino de Vera s/n, 46022 \\ Valencia, Spain \\ *Corresponding author. Tel.: +34 963879910. E-mail address: jacervaz@iie.upv.es
}

\begin{abstract}
In order to optimize the global energy performance of a ground source heat pump system, special attention needs to be paid to the auxiliaries as they stand for a considerable part of the total energy consumption. A new in situ experimental methodology based on the frequency variation of the water circulation pumps in order to optimize the energy performance of the system was previously published by the authors for a ground source heat pump system using a single stage heat pump with ON/OFF regulation. The original single stage heat pump was recently replaced with a multistage unit consisting of two compressors of the same capacity working in tandem. A new experimental campaign was carried out and a new study was performed in order to adapt the in situ optimization methodology to the performance of the tandem compressors unit, and, by extension, to the multistage case. This paper presents the in situ optimization methodology for the water circulation pumps frequency adapted for multistage ground source heat pump systems. Results show that energy savings up to $32 \%$ can be obtained by applying this optimization methodology.
\end{abstract}

Keywords: Heating/cooling systems; ground source heat pump; energy efficiency; auxiliaries.

\section{INTRODUCTION}

In the current context of global warming concern, special attention should be paid to the efficient use of renewable energies. Ground source heat pump (GSHP) systems, which take advantage of shallow geothermal energy, are widely considered as being among the most efficient and comfortable heating and 
cooling renewable technologies currently available [1]. They can lead to a $40 \%$ savings in annual electricity consumption, in comparison to air to water conventional heat pumps [2].

Over the last years, research has focused on capacity control, mainly by means of variable speed compressors. For instance, Fahlén and Karlsson compared control for ON/OFF compressor with variable speed control for a brine-to-water heat pump ([3] and [4]). In [5], Madani et al. carried out a comparative analysis of three common control strategies for an ON/OFF controlled ground source heat pump system. In [6], Zhao et al. performed both a theoretical and an experimental analysis in order to match the capacity of a geothermal heat pump system, which used as a low temperature heat source the geothermal discharge water, with the actual load requirement by adjusting the compressor rotation speed by means of a transducer.

However, several studies highlighted the important amount of energy consumed by the auxiliaries (such as water circulation pumps) in air conditioning systems ([7], [8] and [9]) and the necessity of reducing this energy consumption, above all in GSHP systems in which two circulation pumps are required. In [10] Granryd presents analytical expressions for possible optimum flow rates on the secondary loop. In the PhD work by Karlsson [11], a theoretical study shows that there is a potential for applying an optimization method for keeping the compressor and pump speeds at the optimal combination. The key point to find this optimal combination is to consider the pump circulation rates optimizing the total power consumption of the system and not only the heat pump power consumption. The authors previously developed an experimental in situ optimization methodology for the water circulation pumps frequency of ground source heat pump systems when single stage ON/OFF regulation is employed [12].

The present paper is focused on describing and applying a similar methodology, also reliant on in situ experimental measurements, in order to optimize the system energy performance when considering multistage ON/OFF regulation. The study was experimentally carried out for a heat pump unit using two compressors of the same capacity working in tandem, and the methodology was adapted to multistage heat pump units with whatever number of compressors.

\section{GEOTHERMAL EXPERIMENTAL PLANT}


The geothermal plant studied in the present work was built in year 2004 during a European project called Geocool [13]. In the framework of another FP7 European project, Ground-med [14], the original heat pump located at the geothermal plant (ON/OFF controlled single stage unit) was replaced with a multistage unit consisting of two compressors of the same capacity working in tandem. Therefore, most of the installation remained unchanged (ground source heat exchanger, hydraulic circuits, etc.) and the main modification was the replacement of the heat pump mentioned above.

The GSHP installation studied in the present work air-conditions a set of spaces in the Department of Applied Thermodynamics at the Universitat Politècnica de València, Spain, with a total area of approximately $250 \mathrm{~m}^{2}$. All rooms are equipped with fan coils supplied by the GSHP system. The geothermal system consists of a reversible water-to-water heat pump (nominal capacity of $17.2 \mathrm{~kW}$ in cooling mode and $19.2 \mathrm{~kW}$ in heating mode), a vertical borehole heat exchanger (grid of $2 \times 3$ boreholes, 3 meter separated from each other, 50 meter deep) and a hydraulic group, as shown in the diagram of the installation in Figure 1.

As it can be observed in Figure 1, the system can be divided into two main circuits: an internal circuit which consists of a series of 12 parallel connected fan coils, an internal hydraulic loop and a water storage tank, and an external circuit which consists of the ground source heat exchanger (GSHX) which is coupled to the heat pump by an external hydraulic loop. A timer controls the overall system operation, which was programmed to operate from $7 \mathrm{am}$ to $10 \mathrm{pm}, 5$ days per week.

Both circuits, internal and external, are provided with circulation pumps which make the water circulate towards the fan coil units (ICP; nominal values at $50 \mathrm{~Hz}$ : $3180 \mathrm{~kg} / \mathrm{h}$ with $0.63 \mathrm{~kW}$ power consumption) and the GSHX (ECP; nominal values at $50 \mathrm{~Hz}: 2650 \mathrm{~kg} / \mathrm{h}$ with $0.36 \mathrm{~kW}$ power consumption). While the internal pump works continuously during the 15 hours per day of system operation, the external pump is controlled by the heat pump controller, which makes it work only when at least one of the compressors is running. Two frequency inverters, one for each circulation pump, were installed in order to vary the internal and external circuit water flow rates. A network of sensors was set up so that the installation is completely monitored: water temperatures (four-wire PT100 with accuracy $\pm 0.1^{\circ} \mathrm{C}$.), mass flow rates (Danfoss flow meter model massflo MASS 6000 with accuracy $<0.1 \%$ ) and power consumptions (Gossen Metrawatt power meter model A2000 with accuracy $\pm 0.5 \%$ ). 
Further details on the system description can be found in previous publications ([12] and [13]).

\section{THEORY AND CALCULATION}

\subsection{IMPACT OF WATER FLOW RATES ON THE SYSTEM ENERGY PERFORMANCE}

When optimizing the overall system performance of a GSHP installation, it is important to understand how the increase of the circulating water flow rate affects the performance of the heat pump and that of the entire system. In a given system, the higher the inverter frequency, the greater the circulating water flow rate. A higher water flow rate enhances the heat transfer coefficient through the heat exchanger of the heat pump and diminishes the water temperature variation across it; the same happens at the GSHX. On the heat pump side, the increase of the water flow rate helps to reduce the temperature difference between the water and the refrigerant and, as a result, the temperature lift that the compressor must overcome becomes lower and the heat pump COP increases [12]. This can be observed in Figure 2, which shows experimental results of the effect of varying the water flow rates (proportional to the frequencies, which were set at the same value when measuring the different experimental points) in both the heat pump COP (COP HP) and the system COP (COP sys). It is clearly noted that the higher the flow rate at both the external and internal circuit, the better the performance of the heat pump (COP HP). Nevertheless, when the whole system is considered, operating at maximum flow rates (maximum frequencies) results in a great reduction of the system COP due to the big influence of the circulation pumps consumption.

In a few words, increasing the water flow rate on both sides of the heat pump (evaporator and condenser) diminishes the compressor consumption but increases the circulation pumps consumption. These two opposite trends on energy consumption result in an optimum frequency for each one of the water loops. This paper describes the in situ methodology to determine those optimum frequencies for a multistage heat pump unit.

\subsection{PARTIAL LOAD RATIO OF THE SYSTEM}

When analyzing a multistage heat pump unit, which consists of a specific number of compressors $(\boldsymbol{N})$ working in tandem, special attention should be paid to the thermal demand of the building, since it will 
determine the number of stages in operation and thus the compressor consumption. It should be noted that the greater the number of stages switched on, the higher the compressor consumption and the lower the impact of the water circulation pumps on the total system consumption. Therefore, the thermal demand of the building must be taken into account since it will have a big influence on the determination of the optimal pair of frequencies.

A parameter that stands for the thermal demand of the building is the partial load ratio of the system, which can be defined as the relation between the instantaneous thermal load of the building $\left(\dot{\boldsymbol{Q}}_{\boldsymbol{B}}\right)$ and the heat pump capacity $\left(\dot{\boldsymbol{Q}}_{\boldsymbol{H P}}\right)$. For a single stage ON/OFF controlled heat pump, as the one studied in [12], the partial load ratio of the system can be calculated by means of equation (1), where $\boldsymbol{t}_{\boldsymbol{O} \boldsymbol{N}}$ and $\boldsymbol{t}_{\boldsymbol{O F F}}$ are the duration of the $\mathrm{ON}$ and $\mathrm{OFF}$ cycles respectively.

$\alpha=\frac{t_{O N}}{t_{O N}+t_{O F F}}$

However, a multistage heat pump has a slightly different performance, which makes it necessary to define a parameter that characterizes its operation state, referred to in the following as $\boldsymbol{n}$. Therefore, for a given state $\boldsymbol{n}$, there will be $\boldsymbol{n}-\mathbf{1}$ compressors working continuously and the $\boldsymbol{n} \boldsymbol{t} \boldsymbol{h}$ compressor cycling ON/OFF. In the particular case considered in this study (two compressors working in tandem), there will be two different operation states: the periods when there is one compressor cycling ON/OFF, as if it was a single stage unit (state $\boldsymbol{n}=\mathbf{1}$ ), and the time when there is one compressor continuously running and the other one switching on and off (state $\boldsymbol{n}=2$ ). Therefore, equation (1) would only be valid for calculating the partial load ratio of each one of the stages and it will be referred to in the following as $\boldsymbol{\alpha}^{\prime}$, in such a way that:

- For state $\boldsymbol{n}=\mathbf{1}, \boldsymbol{t}_{\boldsymbol{O F F}}$ is the time during which the heat pump is switched off and $\boldsymbol{t}_{\boldsymbol{O N}}$ is the time during which only one stage is running.

- For state $\boldsymbol{n}=\mathbf{2}, \boldsymbol{t}_{\boldsymbol{O F F}}$ is the time during which the second stage is switched off and first stage is continuously running; and $\boldsymbol{t}_{\boldsymbol{O} \text { N }}$ is the time during which both compressors are running.

In order to characterize the thermal demand of the building in this kind of multistage heat pump systems, equation (2) is proposed, where $\boldsymbol{N}$ is the total number of compressors of the multistage heat pump unit assuming all of them of the same capacity $\left(\dot{\boldsymbol{Q}}_{\boldsymbol{H P}}=\boldsymbol{N} \cdot \boldsymbol{Q}_{(\mathbf{1})}\right)$, which is not completely true, but allows to simplify the problem. 
$\alpha=\left(1-\alpha^{\prime}\right) \cdot \frac{n-1}{N}+\alpha^{\prime} \cdot \frac{n}{N}$

Figure 3 shows an example of the evolution of the two different states via the control signal of the compressors. It can be observed that the second compressor only starts when the partial load ratio of the system $(\boldsymbol{\alpha})$ is greater than 0.5 .

\subsection{EVALUATION OF ENERGY EFFICIENCY PARAMETERS}

The energy performance of the GSHP installation was described in detail by the authors in a previous publication [12]. Notwithstanding, a brief explanation is presented in this section.

Energy efficiency is characterized by the energy performance factor, defined as the ratio between the thermal load and the electric energy consumption during a time interval. Depending on the duration of the integration period, the energy performance factor can be seasonal, monthly, daily, etc. The most representative one is the seasonal performance factor (SPF), which estimates the system performance during each season (winter or summer). Energy efficiency parameters are therefore calculated from the power consumption readings and the heat transferred from the heat pump to the internal circuit. The latter, which depends on the number of stages switched on, is estimated by means of equation (3).

$\dot{Q}_{(n)}(t)=\dot{m} \cdot c_{p} \cdot\left(T_{o, i c}(t)-T_{i, i c}(t)\right)$

Where:

$\dot{m}$ is the flow rate of water circulating through the internal circuit,

$c_{p}$ is the specific heat at constant pressure, and

$T_{o, i c}$ and $T_{i, i c}$ are the temperatures at the outlet and inlet of the internal circuit respectively.

As presented in [12], in order to characterize the typical performance of the system, a characteristic period ON/OFF can be analyzed. When calculating the performance factor for a single ON/OFF cycle, if only the ON time is considered, the performance factor integrated for one cycle will be the same as the coefficient of performance at steady state conditions, since during the ON cycle time the unit works as in steady state conditions with condensing and evaporating temperatures gliding with the respective inlet water temperatures variation [15]. Therefore, the system coefficient of performance calculated as presented in equation (4) would correspond to the performance of the system under quasi-steady state conditions. 


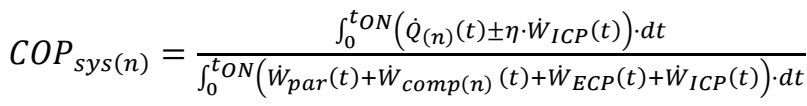

As it can be seen, the denominator of equation (4) includes the power consumption of the whole system, comprising the consumption of the heat pump compressors $\left(\dot{W}_{\operatorname{comp}(n)}\right)$, which depends on the number of stages switched on, the external $\left(\dot{W}_{E C P}\right)$ and internal $\left(\dot{W}_{I C P}\right)$ circulation pumps and the parasitic losses due to the consumption of the electronic devices of the heat pump $\left(\dot{W}_{p a r}\right)$, constant and around $60 \mathrm{~W}$ for the heat pump unit analyzed in this work [15].

Apart from the heat transferred from the heat pump to the internal circuit $\left(\dot{Q}_{(n)}\right)$, calculated through equation (3), the numerator of equation (4) includes the following term: $\pm \eta \cdot \dot{W}_{I C P}$. This term corresponds to the heat transferred to the water as it passes through the internal circulation pump, being $\eta$ the electrical efficiency of the pump (considered as being $\eta=0.9$ for this work). This term should be added to $\dot{Q}_{(n)}$ in heating mode and subtracted from it in cooling mode (that is the reason why the sign \pm appears in the equation).

It is important to notice that both the heat transferred from the heat pump to the internal circuit $\left(\dot{Q}_{(n)}\right)$ and the heat pump power consumption $\left(\dot{W}_{c o m p(n)}\right)$ will depend on the number of compressors running and thus on the state, whether it is $n=1$ or $n=2$ for the particular case of the installation analysed.

Finally, considering both the ON and OFF cycle times for the integration period of equation (4), the performance factor of the system along one entire representative cycle could be calculated by equation (5).

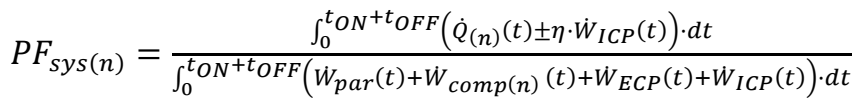

Integrating, equation (5) results in equation (6), which is valid for whatever number of compressors running (n) of a total of $N$ stages.

$P F_{s y s(n)}=\frac{\dot{Q}_{(n-1)} \cdot t_{O F F}+\dot{Q}_{(n)} \cdot t_{O N} \pm \eta \cdot \dot{W}_{I C P} \cdot\left(t_{O N}+t_{O F F}\right)}{\dot{W}_{p a r} \cdot\left(t_{O N}+t_{O F F}\right)+\dot{W}_{c o m p}(n-1)^{\cdot} t_{O F F}+\dot{W}_{C O M p}(n) \cdot t_{O N}+\dot{W}_{E C P} \cdot\left(t_{O N}+t_{O F F}\right)+\dot{W}_{I C P} \cdot\left(t_{O N}+t_{O F F}\right)}$

It should be noticed that in state $n=1$, during the OFF cycle time there is neither heat transferred from the

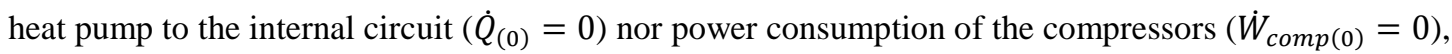
since none of the compressors is running (see Figure 3).

\section{OPTIMIZATION: PROPOSED METHODOLOGY}


In section 4.1, an in-situ experimental methodology in order to obtain the optimum circulation pumps frequency leading to the minimum energy consumption of a GSHP installation using a multistage heat pump unit with two compressors working in tandem is described. It consists of the three steps explained in the following, which are summarized in the flowchart presented in Figure 4. Moreover, a proposal in order to apply this in situ optimization methodology to any installation provided with a multistage heat pump consisting of whatever number of compressors $N$ is presented in section 4.2.

The main advantage of this optimization methodology is that it is based on experimental measurements, thus taking into consideration the real characteristics of the heat pump and the installation when facing the determination of the optimal frequencies. Even with a very detailed model, it is not possible to take into account the wide group of parameters which in practice affects the performance of a geothermal installation, as for instance, the users' daily activity, the ambient temperature variations along the day, the heat transfer to the ground or the fan coils at different flow rates... The proposed methodology is able to consider real operating conditions since it can be carried out in situ at any specific facility.

\subsection{METHODOLOGY FOR A MULTISTAGE HEAT PUMP UNIT WITH TWO COMPRESSORS WORKING IN TANDEM (EXPERIMENTAL CASE)}

\section{Step 1: ON time operation characterization}

The first step consists of several experimental tests of pseudo-random sequence of frequency steps for both, internal and external circulation pumps, carried out during one single day. Figure 5 shows an example of a possible test for the variation of the frequencies of the circulation pumps from $20 \mathrm{~Hz}$ to $55 \mathrm{~Hz}$, minimum and maximum frequencies of the circulation pumps respectively.

The objective of this step is the characterization of the performance of the system during the ON time of the compressor at any possible combination of frequencies. Therefore, each pair of frequencies must be kept constant during a complete ON cycle of the heat pump, which should last, according to the authors' experience, ten minutes or longer in order to obtain sufficient accuracy in the determination of the performance of the system.

Given that the analyzed heat pump consists of two compressors in tandem, the performance will be different whether there is one or there are two compressors running, i.e. only one compressor cycling 
ON/OFF or one compressor continuously running and the other one cycling ON/OFF. Therefore, step 1 tests must be carried out for both operation states $(n=1$ and $n=2)$. For this particular installation, it has been experimentally confirmed that the optimum frequencies are located at higher values when both compressors are running (around $45-50 \mathrm{~Hz}$ ), and hence there is no need for testing frequencies lower than $35 \mathrm{~Hz}$. In the same way, when there is one compressor running the optimum frequencies are around 35-40 $\mathrm{Hz}$ and there is no need for testing frequencies higher than $50 \mathrm{~Hz}$. This is represented in Figure 5, which shows that for $n=1$ the experimental points corresponding to $55 \mathrm{~Hz}$ do not need to be considered (triangles and crosses). Likewise, for $n=2$ the points corresponding to $20 \mathrm{~Hz}$ can be disregarded (squares and crosses). This would allow decreasing the number of experimental points needed from 25 to 16 and hence reducing the required time to carry out the in situ experimental tests.

As recommended in [12], the test should be performed during at least 4 days a year, two during the heating season and two during the cooling season. The reason to propose to repeat the test along one season is to assess the influence of the ground temperature as well as the compensation of the setting for the water return temperature, and confirm whether the optimum remains at the same zone or it requires some readjustment along the season.

Once the tests are finished, the coefficients of performance can be evaluated for each ON cycle so that it will allow the construction of the performance maps of the unit as a function of both the external and internal circulation pumps frequency.

\section{Step 2: Estimation of the system COP maps}

The second step consists of the analysis of the results obtained from step 1, the estimation of the system COP by means of equation (4) and finally their representation in form of maps as a function of the circulation pumps frequency. Figure 6 shows the resulting system COP maps for one typical heating (Figures 6a (one compressor) and 6b (two compressors)) and one typical cooling day (Figures 6c (one compressor) and 6d (two compressors)). The optimal pair of frequencies shown in Figure 6 for each case corresponds to quasi-steady state working conditions.

\section{Step 3: Estimation of the system performance maps for any building thermal load}


The quasi-steady state performance maps of the unit were obtained during the ON cycle time. However, during the OFF time period the power consumption is not zero, due to the internal pump operation $\left(\dot{W}_{I C P}\right)$ ( since it works continuously during the 15 hours of system operation) and to the parasitic losses of the heat pump $\left(\dot{W}_{\text {par }}\right)$, which can significantly degrade the daily performance factor of the system. This third step allows taking into account this influence and calculating, from the quasi-steady state performance maps obtained in step 2 of the methodology, the optimal frequencies as a function of the thermal load of the building $(\alpha)$. Considering equation (6) and the definition of the partial load ratio of each stage $\left(\alpha^{\prime}\right)$, equations (10) and (11) can be obtained.

$\begin{aligned} P F_{s y s(n=1)} & =\frac{\operatorname{COP}_{s y s(1)} \pm \frac{\eta \cdot \dot{W}_{I C P}}{\sum \dot{W}_{(1)}} \cdot \frac{(1-\alpha \prime)}{\alpha^{\prime}}}{1+\frac{\left(\dot{W}_{p a r}+\dot{W}_{I C P}\right)}{\sum \dot{W}_{(1)}} \cdot \frac{(1-\alpha \prime)}{\alpha^{\prime}}} \\ P F_{s y s(n>1)} & =\frac{\operatorname{COP}_{s y s(n-1)} \cdot \frac{(1-\alpha \prime)}{\alpha^{\prime}} \cdot \frac{\sum \dot{W}_{(n-1)}}{\sum \dot{W}_{(n)}}+\operatorname{COP}{ }_{s y s(n)}}{\frac{\left.\sum \dot{W}_{(n-1)}\right)}{\sum \dot{W}_{(n)}} \cdot \frac{\left(1-\alpha^{\prime}\right)}{\alpha^{\prime}}+1}\end{aligned}$

Where:

$\sum \dot{W}_{(n)}=\dot{W}_{c o m p(n)}+\dot{W}_{p a r}+\dot{W}_{E C P}+\dot{W}_{I C P}$

It should be noticed that, in equations (7) and (8), $\dot{W}_{\text {comp }(n-1)}, \dot{W}_{c o m p(n)}, \dot{W}_{p a r}, \dot{W}_{E C P}$ and $\dot{W}_{I C P}$ correspond to power measurements obtained in step 1 of the methodology; $C O P_{s y s(n-1)}$ and $C O P_{s y s(n)}$ correspond to the quasi-steady system COP obtained in step 2 of the methodology; finally, $\alpha^{\prime}$ is the partial load ratio of each one of the stages (one ON/OFF compressor running or two compressors in tandem).

It can be checked in equations (7) and (8) that, when the partial load ratio of each stage is $\alpha^{\prime}=1$, the system performance factors take the same values as in quasi-steady state conditions $\left(P F_{s y s}=C O P_{s y s}\right)$.

Step 3 consists of the extrapolation of the performance maps characterization at quasi-steady state conditions to any partial load ratio of the system $(\alpha)$. By means of equations (7) and (8), it is possible to obtain the system performance factor $\left(P F_{s y s}\right)$ as a function of the partial load ratio of each stage $\left(\alpha^{\prime}\right)$. However, since the aim of the step 3 of the methodology is to obtain $P F_{s y s}$ as a function of $\alpha$, it is necessary to relate these two parameters. For that purpose, the relation between $\alpha$ and $\alpha^{\prime}$ given by equation (2) will be considered. Figures 7 and 8 show, for heating and cooling mode respectively, the system 
performance factor maps as a function of the water circulation pumps frequency for four different values of the partial load ratio of the system.

\subsection{PROPOSED METHODOLOGY FOR A MULTISTAGE HEAT PUMP UNIT WITH "N" COMPRESSORS (GENERAL CASE)}

The optimization methodology developed was experimentally applied to a geothermal plant with a multistage heat pump unit with two compressors of the same capacity working tandem. Notwithstanding, it can be applied to any other installation having a multistage heat pump unit with more than two compressors. This section presents a proposal in order to apply the in situ optimization methodology to any installation provided with a multistage heat pump consisting of whatever number of compressors $N$.

\section{Step 1: ON time operation characterization}

When the multistage heat pump unit has more than two stages, the experimental tests from step 1 of the methodology should be repeated at least three times: for the first stage $(n=1)$, for the maximum capacity of the heat pump $(n=N)$ and also for an intermediate stage. This intermediate stage can be chosen by means of the expression provided by equation (9).

$n=\operatorname{int}\left(\frac{N}{2}\right)+1$

Figure 9 shows the different frequency values that should be considered for each one of the three states. It should be pointed out that for $n=\operatorname{int}(N / 2)+1$, and in order to save time, some of the experimental points represented by squares and triangles in Figure 9 (preferably those close to the crosses) could be removed from the test matrix. Since the optimum is usually located at medium frequencies for partial load ratios around 0.5 , this will not affect the results. However, as it was checked by the authors, considering a number of points less than 15 would result in a loss of resolution and in the optimum not being accurately determined. Therefore, a total number of at least 15 points is recommended.

\section{Step 2: Estimation of the system COP maps}

Given that the experimental tests from the first step should be carried out for three times, the results of step

2 for a multistage heat pump with $N$ compressors should be three system COP maps for each mode (heating or cooling), one for each of the three states analyzed. 


\section{Step 3: Estimation of the system performance maps for any building thermal load}

Step 3 can be applied in the same way as for the two tandem compressors heat pump, since equation (8) can be applied to any number of stages.

\section{RESULTS AND DISCUSSION}

The optimization methodology developed in this work allows the characterization of the system COP (Figure 6) and the system performance factor, PF, (Figures 7 and 8), and finally the determination of the optimal pair of frequencies that maximize the system performance factor as a function of the building thermal load.

Figures $6 a$ and $6 \mathrm{c}$ show the system COP maps for the heat pump operating with one compressor. It is clearly observed in Figure 6a that the influence of the internal pump is higher than that of the external pump, since the latter presents a higher value of the optimal frequency, what means that the internal circulation pump consumption represents a greater penalty in the energy performance of the system. This is because, for a similar flow rate, the head losses are higher in the internal circuit due to the distribution network of 12 fan coils distributed in each of the air conditioning spaces, what results in a greater pumping power for the internal circulation pump. In general, the optimums in Figures $6 \mathrm{a}$ and $6 \mathrm{c}$ correspond to low frequencies (between $30 \mathrm{~Hz}$ and $35 \mathrm{~Hz}$ ) because the influence of the consumption of the circulation pumps is important in comparison to the total consumption, as there is only one compressor working.

In contrast, when the heat pump works with two compressors in tandem, the system COP maps become different (Figures $6 \mathrm{~b}$ and $6 \mathrm{~d}$ ). In this case, it is observed that the influence of the circulation pumps is smaller, since the heat pump consumption is higher when both compressors are running, and the optimum frequencies move to higher values (around 45-50 Hz). The dark zone that appears on the lower left corner of figures $6 \mathrm{~b}$ and $6 \mathrm{~d}$ (frequencies of $20-30 \mathrm{~Hz}$ ) corresponds to the points that were removed from the test matrix. Notice that, anyhow, the optimum is clearly located on the right upper corner.

It can also be observed that the COP is higher in cooling mode (Figures $6 \mathrm{c}$ and $6 \mathrm{~d}$ ) than in heating mode (Figures $6 \mathrm{a}$ and $6 \mathrm{~b}$ ). This is mainly because the temperature lift that has to overcome the compressor is higher in heating mode (Source (ground loop) Temperature $=17^{\circ} \mathrm{C}$, Sink Temperature $=40^{\circ} \mathrm{C}$ ) than in cooling mode (Source (ground loop) Temperature $=25^{\circ} \mathrm{C}$ approximately, Sink Temperature $=10^{\circ} \mathrm{C}$ ). These 
source temperatures correspond to experimental measurements, being the undisturbed ground temperature $18.5^{\circ} \mathrm{C}$. Further details can be found in [12] and [13].

Several tests were carried out at the installation along the year during each working mode and, even though the system COP maps were not exactly the same, results confirmed similar trends and very similar locations for the optimums with an uncertainty of $\pm 5 \mathrm{~Hz}$.

Figures 7 and 8 show, for heating and cooling mode respectively, the system PF maps as a function of the water circulation pumps frequency for four different values of the partial load ratio of the system $(\alpha=0.1$, $0.3,0.5,0.8)$. Notice that the second compressor only switches on for partial load ratios greater than 0.5 , as previously shown in Figure 3. This means that, while the $P F_{s y s}$ maps for $\alpha$ values up to 0.5 correspond to the heat pump working with one stage, the $P F_{s y s}$ maps for $\alpha$ values greater than 0.5 correspond to two compressors working in tandem (Figures $7 \mathrm{~d}$ and $8 \mathrm{~d}$ ).

Taking the example of heating mode (Figure 7), it can be observed that the performance of the system degrades for low partial load ratios (Figure 7a). This is due to the auxiliary equipment consumption (external and internal pumps consumption and parasitic losses), which have a great influence in the system performance factor. Moreover, it can be observed that the influence of the internal pump is higher than that of the external pump given the higher value of the optimal frequency for the latter. In this case, when the performance factor (PF) is considered (what means that the OFF cycle time is also considered for the calculation of the performance factor), this effect is not only due to larger head losses in the internal circuit, but also (and mainly) because of a larger time of operation for the internal pump, which is continuously running during the 15 hours per day of system operation.

As the partial load ratio increases, the system performance factor improves until it reaches a maximum value of 4.58 for $\alpha=0.5$ (Figure 7c). The optimal frequencies are low because, as there is only one compressor running, the influence of the pumps power consumption is much greater. On the contrary, when the thermal load of the building gets higher and the second stage switches on, the optimal frequencies come to higher values, around $45-50 \mathrm{~Hz}$ (Figure 7d). This is because both compressors are running, so the consumption of the auxiliaries represents a smaller percentage of the total energy consumption. Very similar trends can be seen for cooling mode. Again, the values of the optimal COPs are higher in cooling than in heating mode. 
Figure 10 presents the optimal frequencies for each mode (heating or cooling) and for each circulation pump (internal and external). It can be clearly observed that, the higher the partial load ratio, the higher the values for the optimal frequencies.

The expressions shown in Figure 10 were implemented in LabVIEW so that the optimal frequencies were automatically calculated at each moment and set in the frequency inverters in order to obtain energy savings. These are part of an integrated optimization algorithm in which other parameters are also considered. For instance, the temperature setting of the heat pump unit is varied depending on the ambient temperature in order to make the temperature of the water to be supplied to the building ( $T_{S B}$ in Figure 1) remain at the required value. The description of the full algorithm is out of the scope of the present work and will be presented in future publications.

For the time being, the integrated optimization algorithm was experimentally tested on the geothermal plant for a period of several months during the heating season from January to April 2013 and the energy performance of the system was analyzed. In order to perform a proper analysis and carry out a fair comparison, the optimized control was compared to a standard control. This standard control consists of keeping constant the temperature setting $\left(T_{S B}\right)$ at $40^{\circ} \mathrm{C}$, and keeping a fixed frequency $50 \mathrm{~Hz}$ for both circulation pumps. This is how common installations work: fixed temperature setting and $50 \mathrm{~Hz}$ (the frequency of the power supply) to the circulation pumps, with no frequency inverters installed. The controller was programmed in such a way that the standard control is applied on odd days and the optimized control is used on even days. This is a good method for randomly choosing when to apply each control strategy and obtaining, in the end, $50 \%$ of the days working with each one. Possible uncertainties related to the variation of the thermal demand of the building on different days will affect equally to both controls, since the number of days of the study is large enough (the study is intended for a complete season). Figure 11 shows the comparison between both types of control: optimized versus standard. Figure 11a shows, from left to right, the daily performance factors DPF1 (includes only heat pump consumption), DPF2 (includes heat pump and external circulation pump consumption) and DPF3 (includes heat pump and both circulation pumps consumption), for both types of control during two typical heating days (standard control: January $25^{\text {th }} 2013$; optimized control: January $24^{\text {th }} 2013$ ). For the standard day, the average source temperature (ground loop) was $16.2^{\circ} \mathrm{C}$ and the average sink temperature (building supply 
temperature) was $39.6^{\circ} \mathrm{C}$, while for the optimized day the average source temperature (ground loop) was $16.5^{\circ} \mathrm{C}$ and the average sink temperature (building supply temperature) was $35.2^{\circ} \mathrm{C}$. As it can be observed, by applying the optimized control, a $29 \%$ of energy savings were obtained for a single day. Taking into account the accuracy values of the different sensors presented in section 2 , the uncertainty propagation for the calculations of the energy savings of one typical day results in $\pm 1 \%$ approximately. Therefore the energy savings for this single day would take values of $(29.4 \pm 0.3) \%$. When considering the whole period analyzed in the present study (from January to April 2013), the uncertainty obtained is even lower $( \pm 0.21 \%)$.

On the other hand, Figure 11b shows the seasonal performance factors SPF1 to SPF3 for the period when the experimental test campaign was carried out during heating mode (from January to April 2013). During that period, both the average source and sink temperatures may vary for different days, depending on the evolution of the ground temperature and the ambient temperature respectively. The maximum variation observed was $4^{\circ} \mathrm{C}$ for average source temperature (ground loop) and $5^{\circ} \mathrm{C}$ for the average sink temperature (building loop). Results show that energy savings of $(31.70 \pm 0.07) \%$ were obtained by applying the optimized control. It should be noticed that the fan coils are not being optimized for the moment, so future work will be dedicated to the analysis of the impact of the control strategies in the user comfort, taking special attention to the control of the fan coils.

Finally, it should be noted that the energy savings shown in Figure 11 correspond to the application of the integrated optimization algorithm and not only to the variation of the circulation pumps frequency according to the methodology described in this paper. Still, it is the variation of the circulation pumps that accounts for most of the energy savings, since the variation of the temperature setting of the heat pump only stands for around $4 \%$ of the energy savings per degree of variation of the temperature setting, as presented in [13].

\section{CONCLUSIONS}

An in situ optimization methodology based on the frequency variation of the water circulation pumps for ground source heat pump (GSHP) systems with multistage heat pump units was presented in this paper. The methodology previously developed and published by the authors for single stage heat pump units with 
ON/OFF regulation was adapted for multistage heat pump units. Experimental tests were carried out for a heat pump unit with two compressors of the same capacity working in tandem in an institutional building at the Universitat Politècnica de València.

By applying the optimization methodology, an expression that relates the optimal frequency to the partial load ratio of the system $(\alpha)$ was obtained for each working mode (heating or cooling) and for each circulation pump (internal or external), and it was implemented in the control board of the system. The system was continuously monitored during several months in heating mode, from January to April 2013, and the optimized control was compared to a standard one. For a typical heating day, (29.4 \pm 0.3$) \%$. of energy savings were observed (source temperature: $16.2^{\circ} \mathrm{C}$ for standard day and $16.5^{\circ} \mathrm{C}$ for optimized day; sink temperature: $39.6^{\circ} \mathrm{C}$ for standard day and $35.2^{\circ} \mathrm{C}$ for optimized day). Considering the whole analyzed period, energy savings of $(31.70 \pm 0.07) \%$ were obtained.

In addition to the experimental study for two compressors working in tandem, the same optimization methodology was adapted and proposed for multistage heat pump units with whatever number of compressors.

Finally, given that the in situ optimization methodology has been developed for both single stage and multistage heat pump units with ON/OFF regulation, further studies will focus on the adaptation of the methodology to GSHP installations with variable speed heat pump units.

\title{
ACKNOWLEDGEMENTS
}

This work was supported by the "Programa de Ayudas de Investigación y Desarrollo (PAID)" of the Universitat Politècnica de València. This work was also supported by the European FP7 project “Advanced ground source heat pump systems for heating and cooling in Mediterranean climate" (GROUND-MED).

\section{NOMENCLATURE}

\author{
Symbol \\ $C O P_{\text {sys }} \quad$ System coefficient of performance \\ $c_{p} \quad$ Specific heat at constant pressure \\ $\dot{m} \quad$ Internal circuit flow rate \\ $n \quad$ Operation state of the heat pump unit \\ $N \quad$ Total number of compressors of the heat pump unit \\ $P F_{\text {sys }} \quad$ System performance factor
}




$\begin{array}{ll}\dot{Q}_{B} & \text { Instantaneous thermal load of the building } \\ \dot{Q}_{H P} & \text { Heat pump capacity } \\ \dot{Q}_{(n)} & \text { Capacity of } n \text { stages } \\ T_{o, i c} & \text { Temperature at the outlet of the internal circuit } \\ T_{i, i c} & \text { Temperature at the inlet of the internal circuit } \\ T_{S B} & \text { Building supply temperature } \\ t_{O N} & \text { Duration of the ON cycle } \\ t_{O F F} & \text { Duration of the OFF cycle } \\ \dot{W}_{p a r} & \text { Parasitic losses of the heat pump unit } \\ \dot{W}_{c o m p} & \text { Compressor power consumption } \\ \dot{W}_{E C P} & \text { ECP power consumption } \\ \dot{W}_{I C P} & \text { ICP power consumption } \\ \text { Greek symbols } \\ \alpha & \text { Partial load ratio of the system } \\ \alpha^{\prime} & \text { Partial load ratio of each stage of the heat pump unit } \\ \eta & \text { Electrical efficiency of ICP } \\ \text { Acronyms } & \text { Ground source heat pump } \\ \text { GSHP } & \text { Ground source heat exchanger } \\ \text { GSHX } & \text { Groulernal circulation pump } \\ \text { ICP } & \text { Internation pump } \\ \text { ECP } & \text { External circula }\end{array}$

\section{REFERENCES}

[1] EPA. 2010. Energy Star Program from US Environment Protection Agency (Last access 2013/11/19): http://www.energystar.gov/index.cfm?fuseaction=find_a_product.showProductGroup\&pgw_code=HP

[2] Urchueguía, J.F., Zacarés, M., Corberán, J.M., Montero, Á., Martos, J. and Witte, H.: Comparison between the energy performance of a group coupled water to water heat pump system and an air to water heat pump system for heating and cooling in typical conditions of the European Mediterranean Coast, Energy Conversion and Management, 49(10), (2008), 2917-2923.

[3] Fahlén, P. and Karlsson, F.: Improving efficiency of hydronic heat pump heating systems, 21st International Congress of Refrigeration, Washington, USA, (2003).

[4] Fahlén, P. and Karlsson, F.: Optimizing and Controlling Media Flows In Heat Pump Systems, 8th IEA Heat Pump Conference, Las Vegas, USA, (2005).

[5] Madani, H., Claesson, J. and Lundqvist, P.: A descriptive and comparative analysis of three common control techniques for an ON/OFF controlled Ground Source Heat Pump (GSHP) system. Energy and Buildings, 65, (2013), 1-9. 
[6] Zhao, L., Zhao, L.L., Zhang, Q. and Ding, G.L.: Theoretical and basic experimental analysis on load adjustment of geothermal heat pump systems, Energy Conversion and Management, 44, (2003), 1-9.

[7] Bernier, M. and Bourret, B.: Pumping Energy and Variable Frequency Drives, ASHRAE Journal, 41(12), (December, 1999), 37-40.

[8] Brodrick, J.R. and Westphalen, D.: Uncovering Auxiliary Energy Use, ASHRAE Journal, 43(2), (February, 2001), 58-61.

[9] Bsnhfleth, W.P. and Peyer, E.: Variable primary flow chilled water systems: potential benefits and application issues, Report ARTI-21 CR/611-20070-01prepared for the Air-Conditioning and Refrigeration Technology Institute, Arlington, Virginia, US.

[10] Granryd, E.: Analytical expressions for optimum flow rates in evaporators and condensers of heat pumping systems, International Journal of Refrigeration, 33, (2010), 1211-1220.

[11] Karlsson, F.: Capacity control of residential heat pump heating systems, PhD Thesis, Department of Energy and Environment, Chalmers University of Technology, Göteborg, Sweden, (2007).

[12] Montagud, C., Corberán, J.M. and Montero, Á.: In situ optimization methodology for the water circulation pumps frequency of ground source heat pump systems, Energy and Buildings, (2013), doi: 10.1016/j.enbuild.2013.09.030.

[13] Montagud, C., Corberán, J.M., Montero, Á. and Urchueguía, J.F.: Analysis of the energy performance of a ground source heat pump system after five years of operation, Energy and Buildings, 43(12), (2011), 3618-3626.

[14] http://www.groundmed.eu/ (Last access 2013/11/19)

[15] Corberán, J.M., Donadello, D., Martínez-Galván, I. and Montagud, C.: Partialization losses of ON/OFF operation of water to water refrigeration/heat-pump units, International Journal of Refrigeration, 2013, doi: 10.1016/j.ijrefrig.2013.07.002. 
Figure 1: GSHP system diagram.

Figure 2: Influence of the water circulating flow rate on the heat pump and system COP.

Figure 3: Heat pump working state for the tandem compressors heat pump.

Figure 4: Flowchart for the in situ optimization methodology.

Figure 5: Example of a possible test for the variation of the circulation pumps frequency for a two tandem compressors heat pump unit.

Figure 6: $\mathrm{COP}_{\text {sys }}$ quasi-steady state maps as a function of pumps frequency: a) heating 1 compressor; $\mathrm{b}$ ) heating 2 compressors; c) cooling 1 compressor; d) cooling 2 compressors.

Figure 7: $\mathrm{PF}_{\text {sys }}$ maps as a function of pumps frequencies in heating mode: a) $\alpha=0.1$; $\mathrm{b}$ ) $\alpha=0.3$; c) $\alpha=0.5 ;$ d) $\alpha=0.8$.

Figure 8: $\mathrm{PF}_{\text {sys }}$ maps as a function of pumps frequency in cooling mode: a) $\alpha=0.1$; b) $\alpha=0.3$; c) $\alpha=$ $0.5 ;$ d) $\alpha=0.8$.

Figure 9: Proposed test for the variation of the circulation pumps frequencies for a multistage heat pump unit with $\mathrm{N}$ compressors.

Figure 10: Circulation pumps frequency as a function of the partial load ratio: a) ICP heating; b) ECP heating; c) ICP cooling; d) ECP cooling.

Figure 11: Comparison between standard control and optimized control: a) daily performance factors for typical heating days; b) seasonal performance factors for heating mode. 


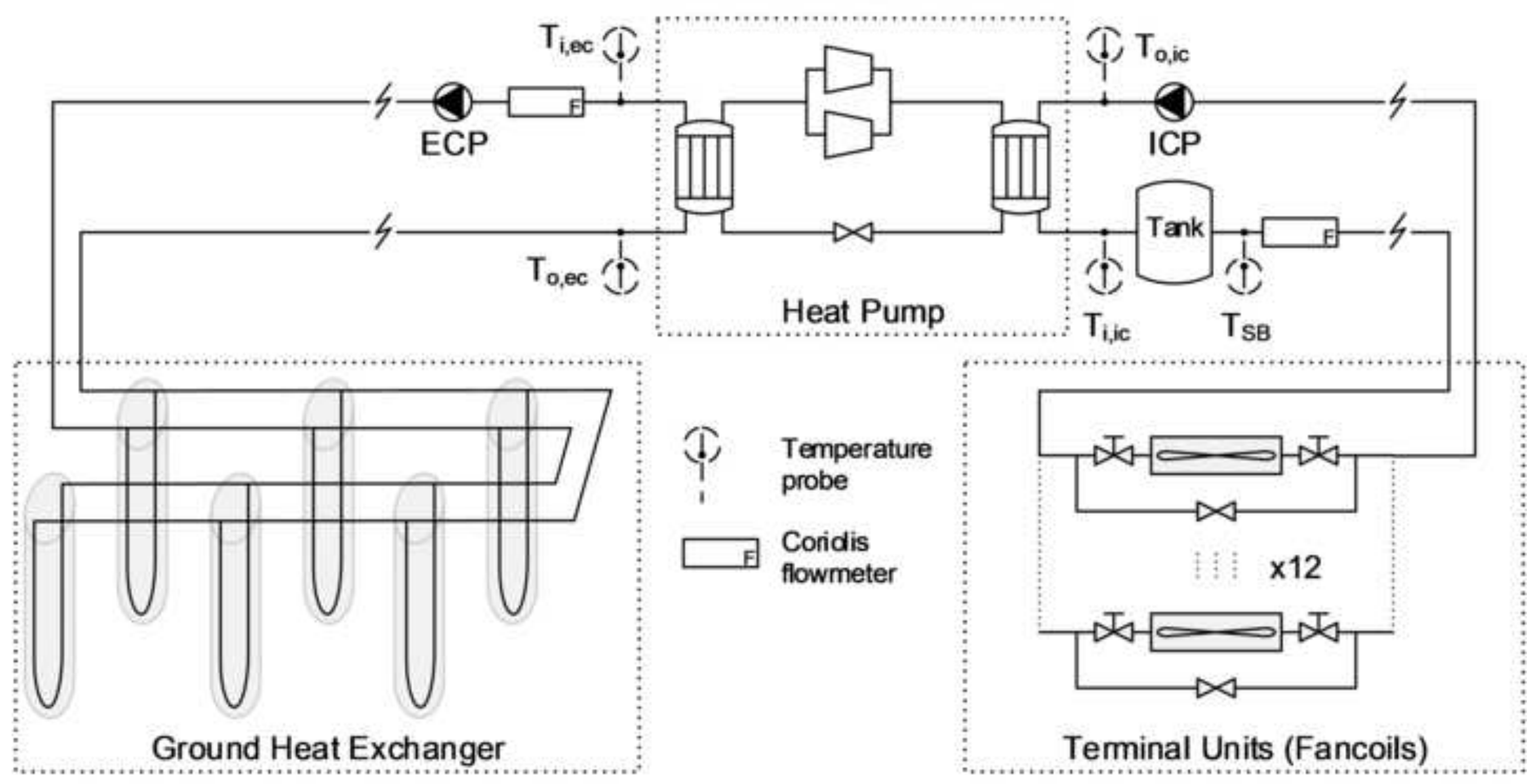




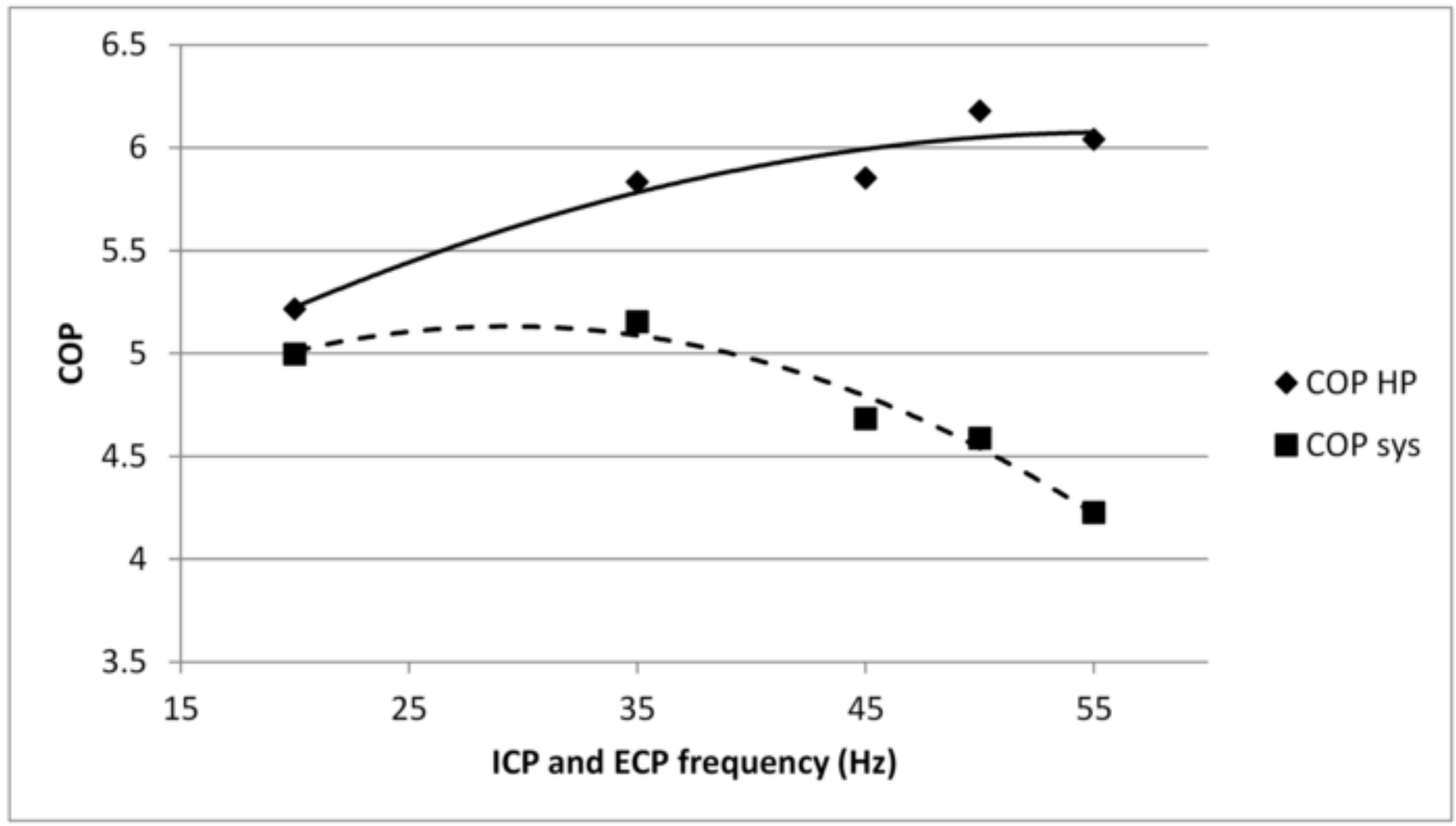




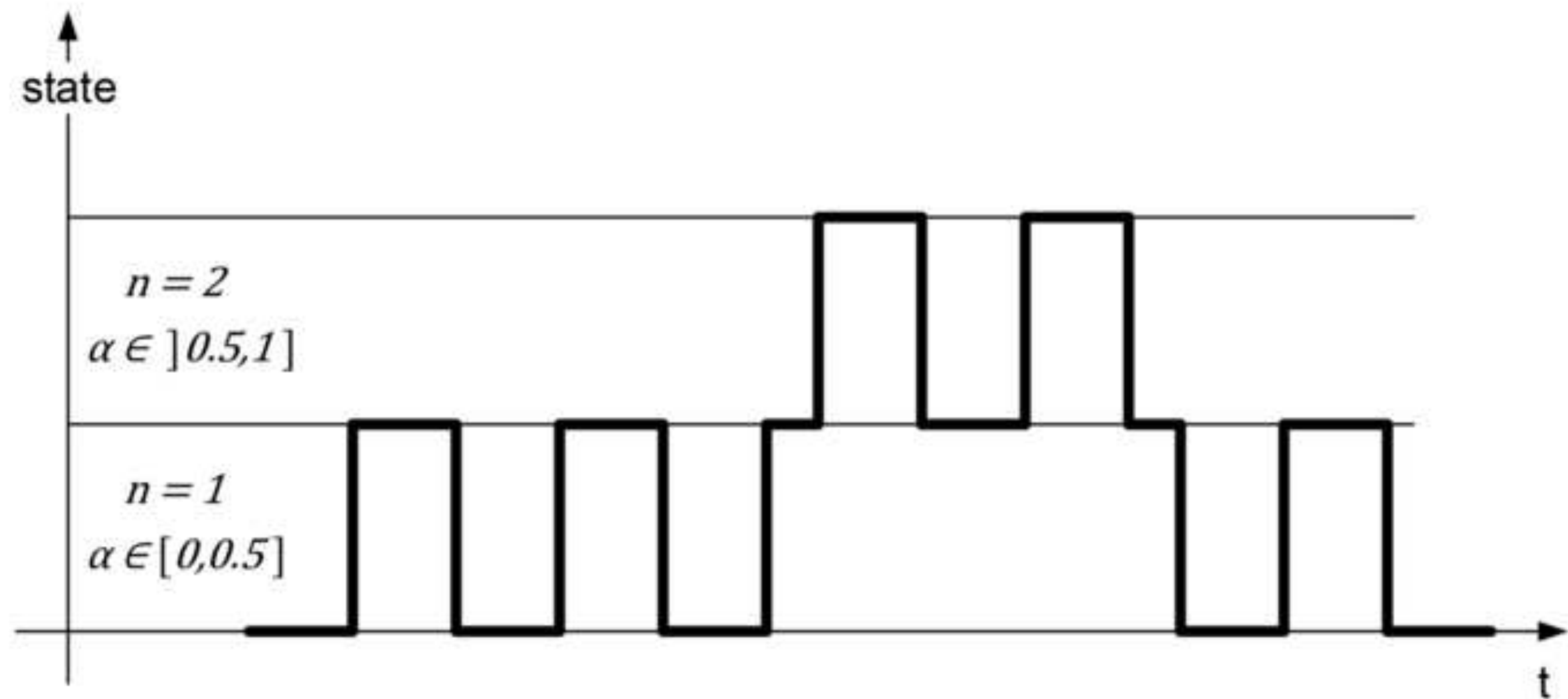

\section{state}

$\alpha \in] 0.5,1]$

$\alpha \in[0,0.5]$ 
Figure 4
Click here to download high resolution image
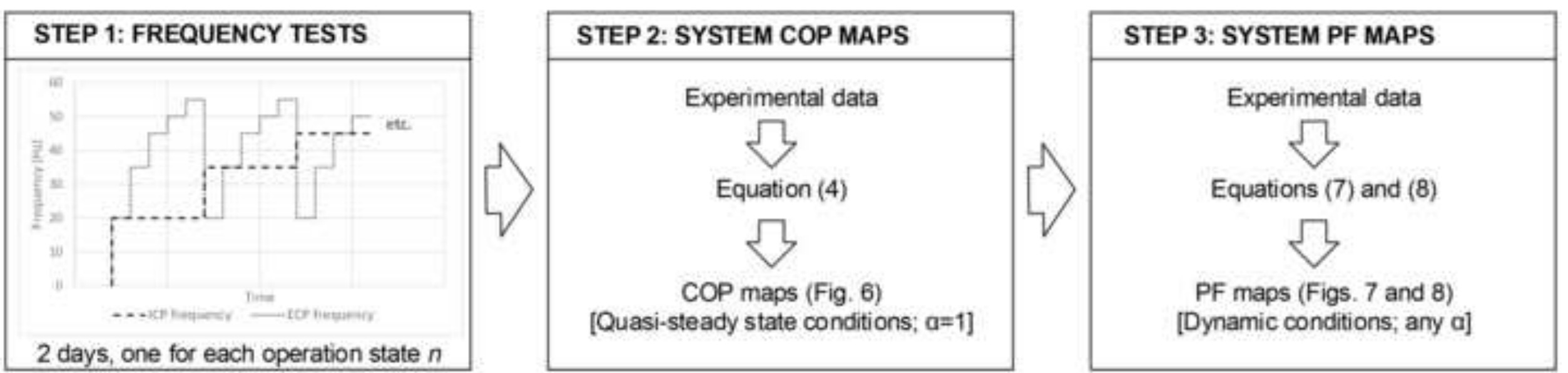


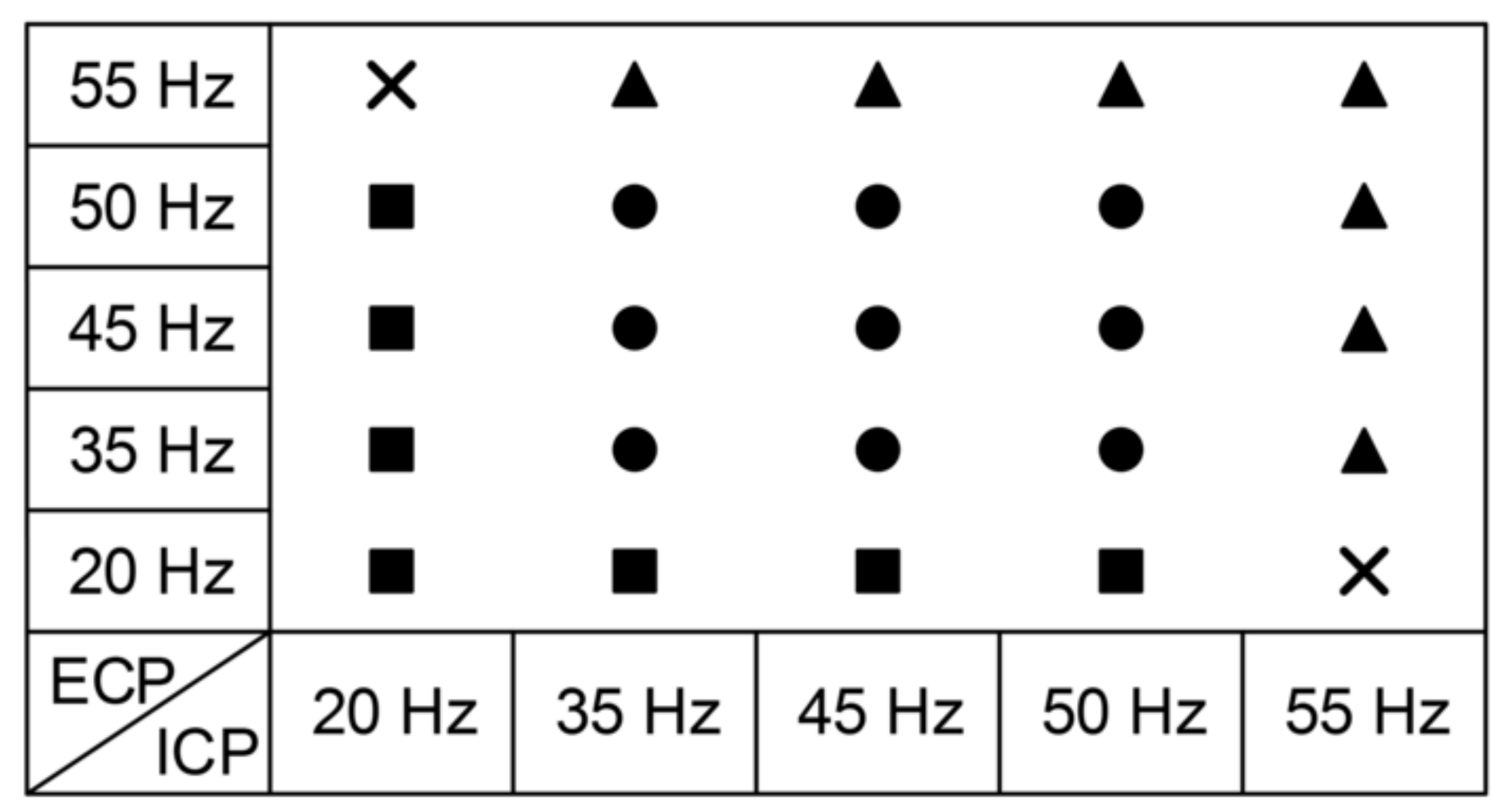

\footnotetext{
Test for $n=1: \boldsymbol{\square}+\boldsymbol{T}$ Test for $\mathrm{n}=2: \boldsymbol{\Delta}+\boldsymbol{\bullet}$
} 
Click here to download high resolution image
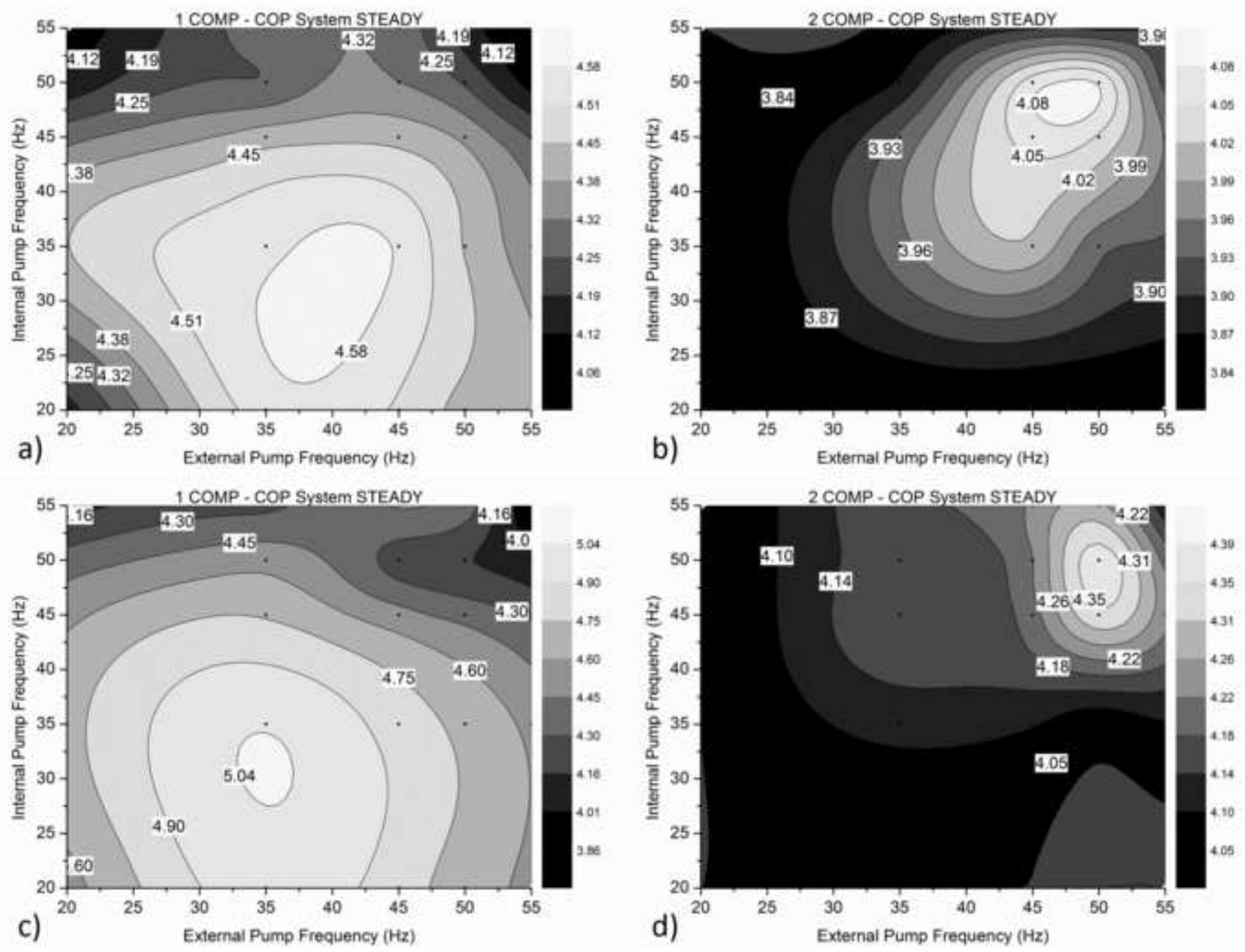

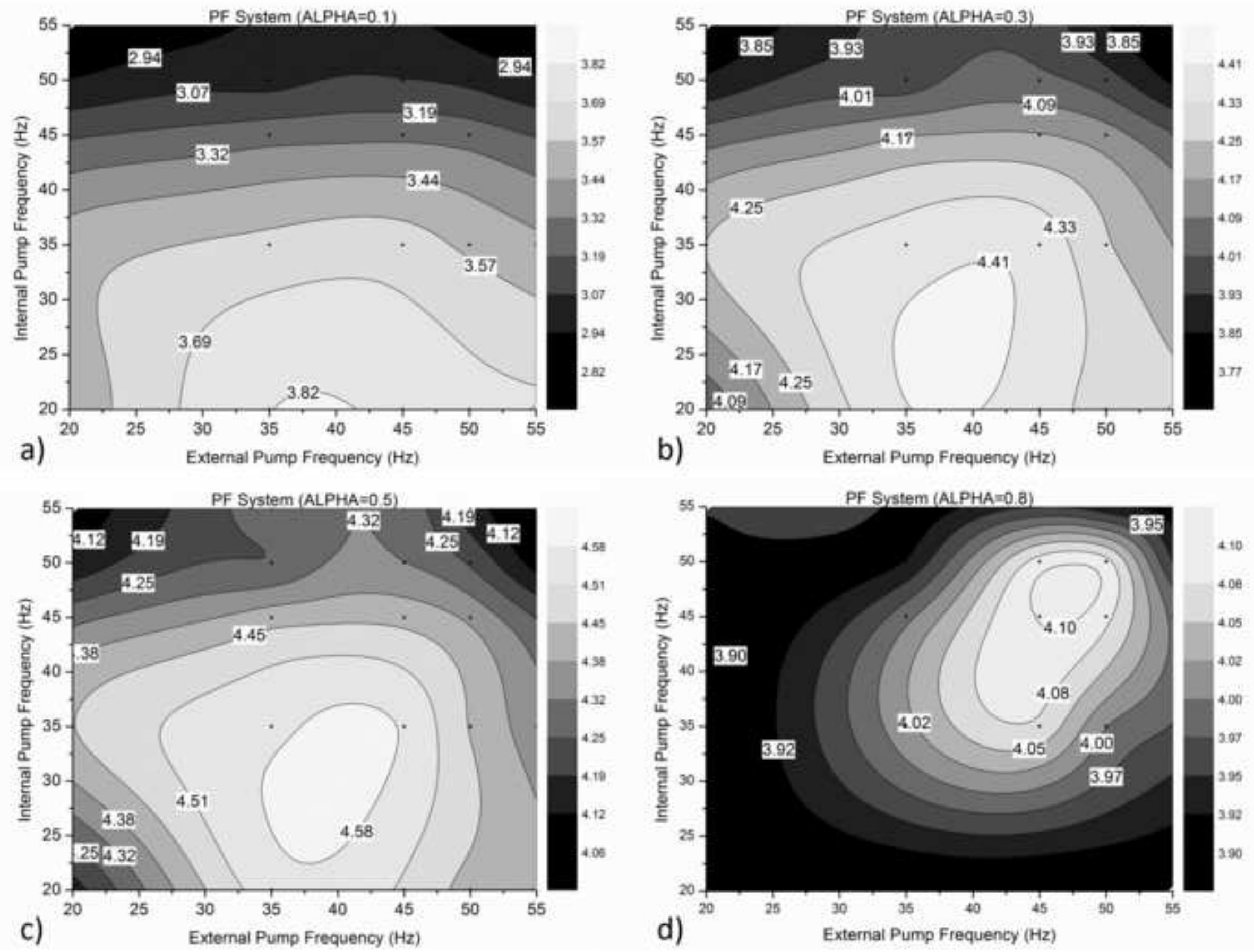

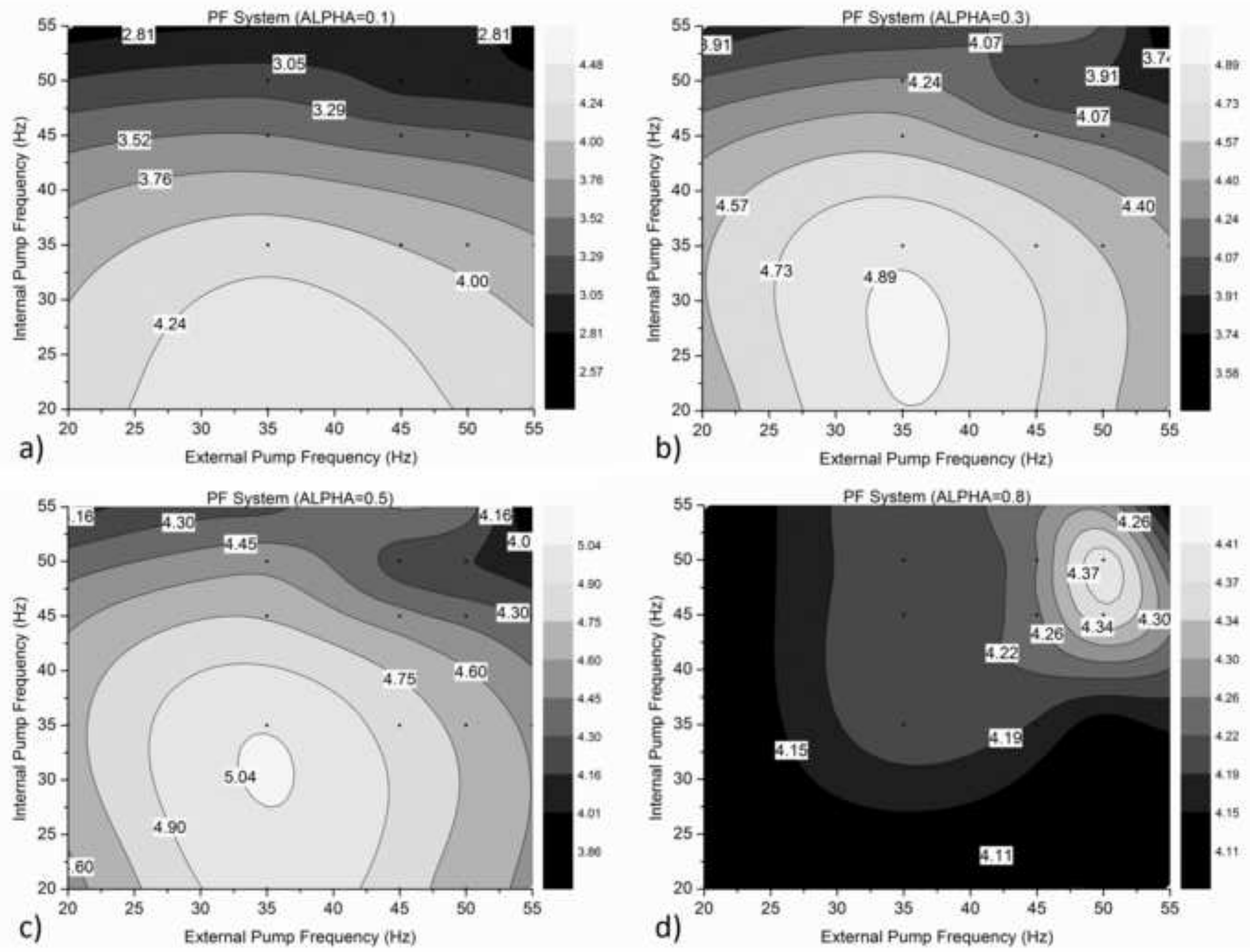


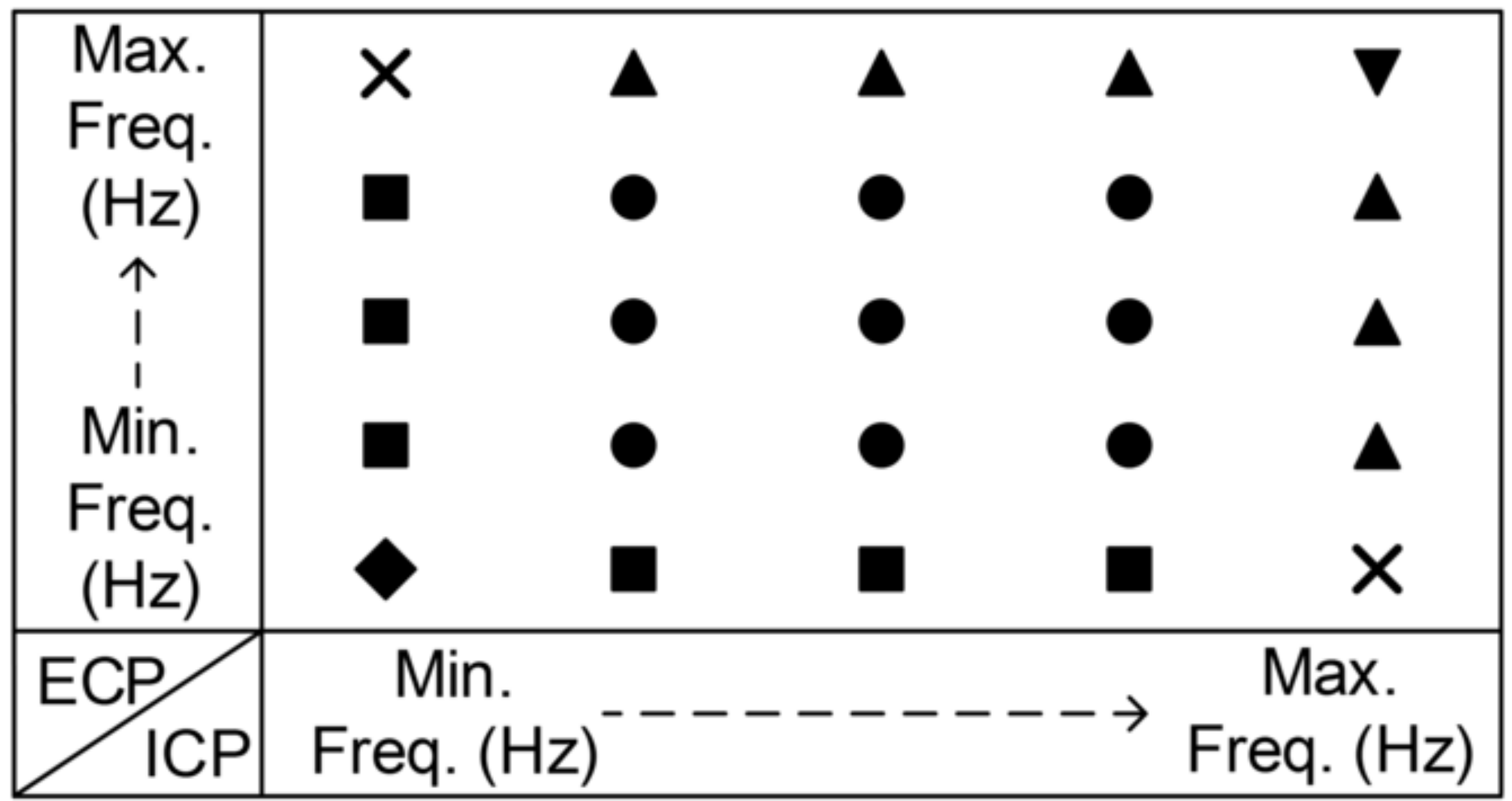

Test for $n=1: \mathbf{a}+\boldsymbol{+}$

Test for $n=\operatorname{int}(\mathrm{N} / 2)+1: \bullet+\mathbf{\square}+\boldsymbol{\Delta}$

Test for $\mathrm{n}=\mathrm{N}: \boldsymbol{\Delta}+\boldsymbol{\nabla}+\boldsymbol{\bullet}$ Freq. (Hz) Min. Freq. $(\mathrm{Hz})$ Freq. $(\mathrm{Hz})$

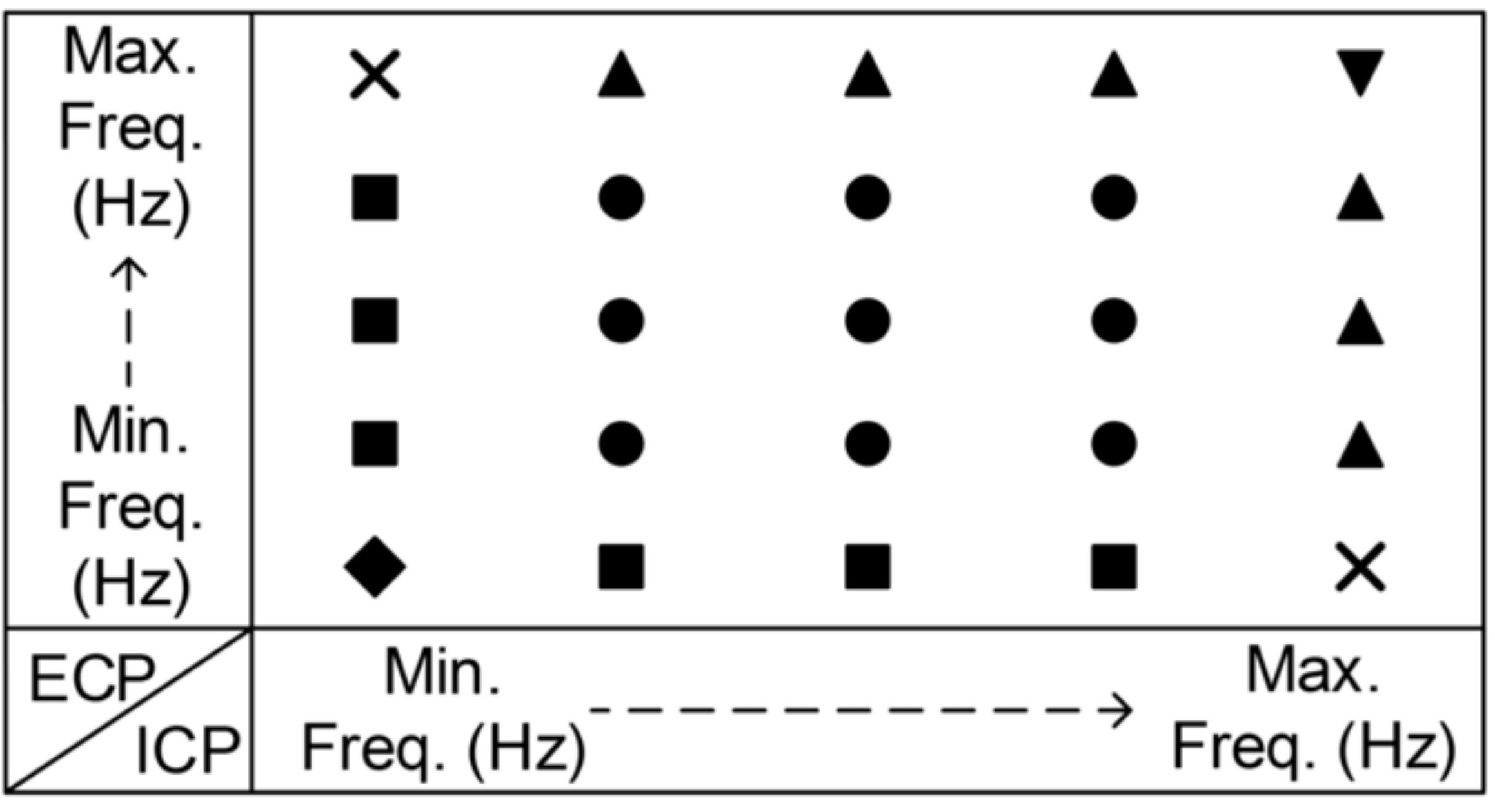


Click here to download high resolution image

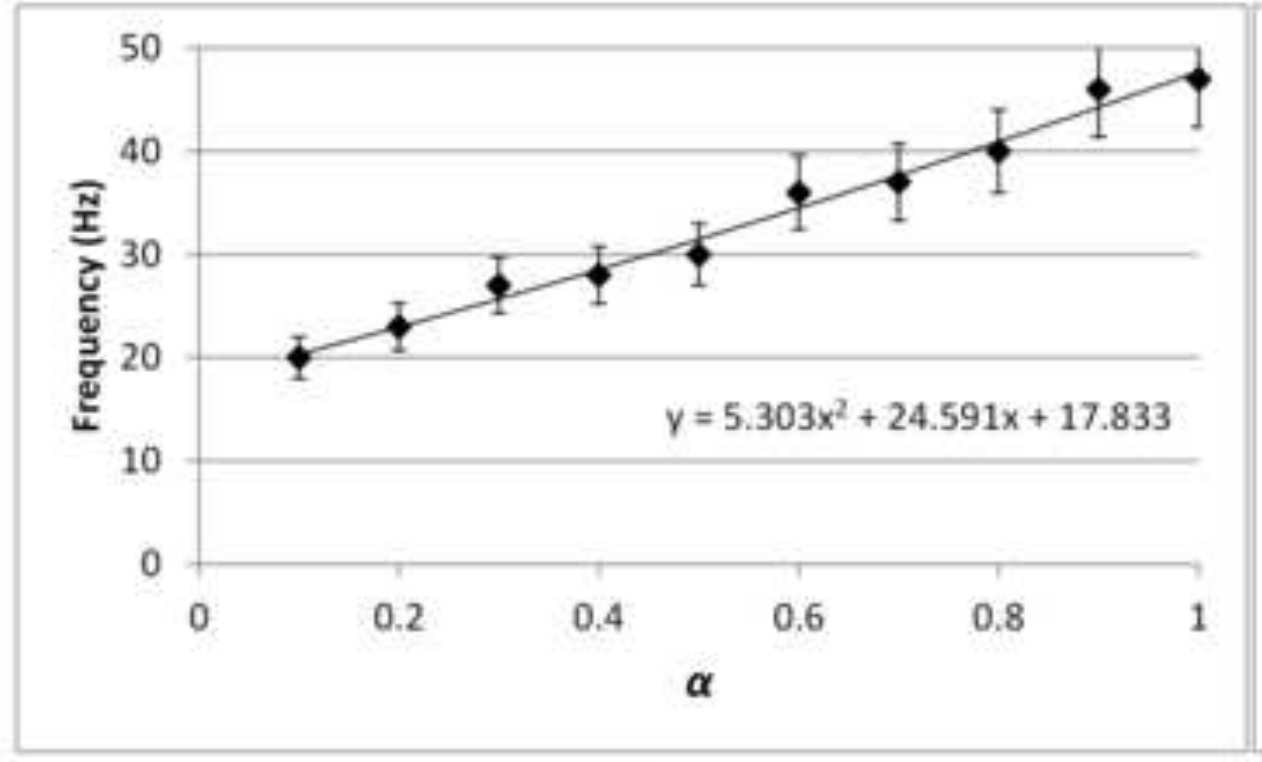

a)

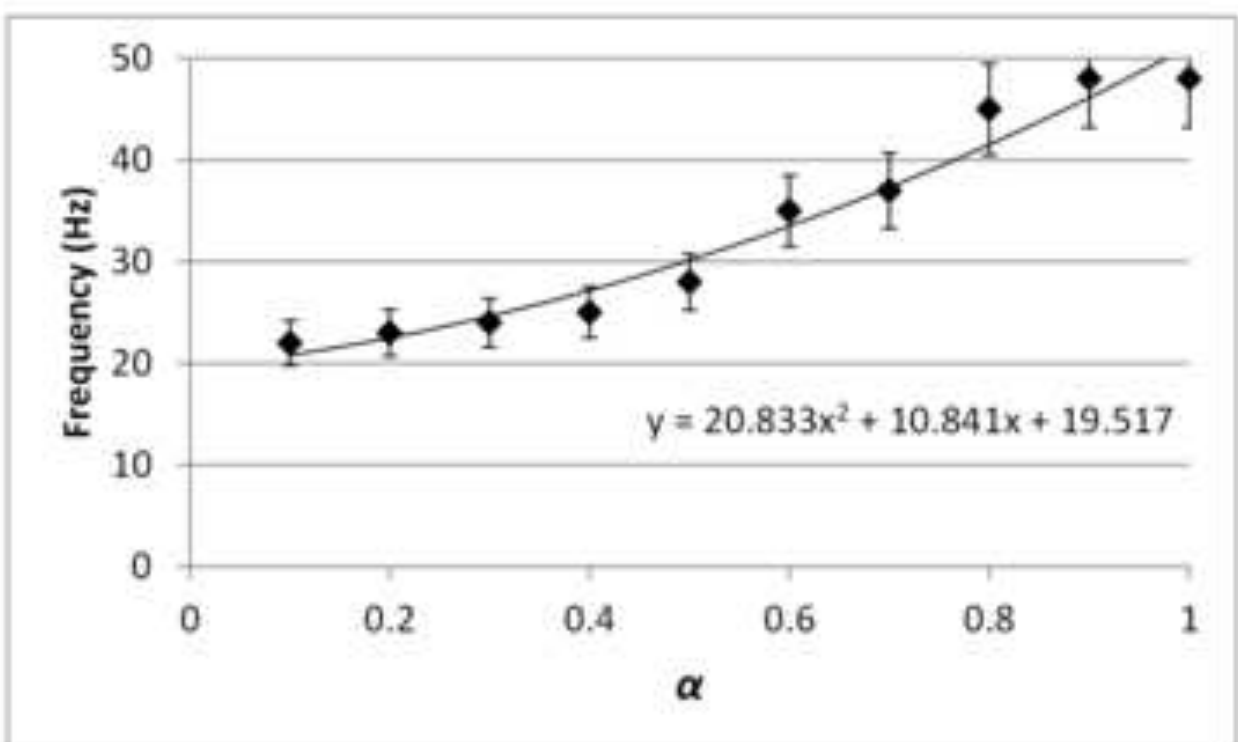

c)

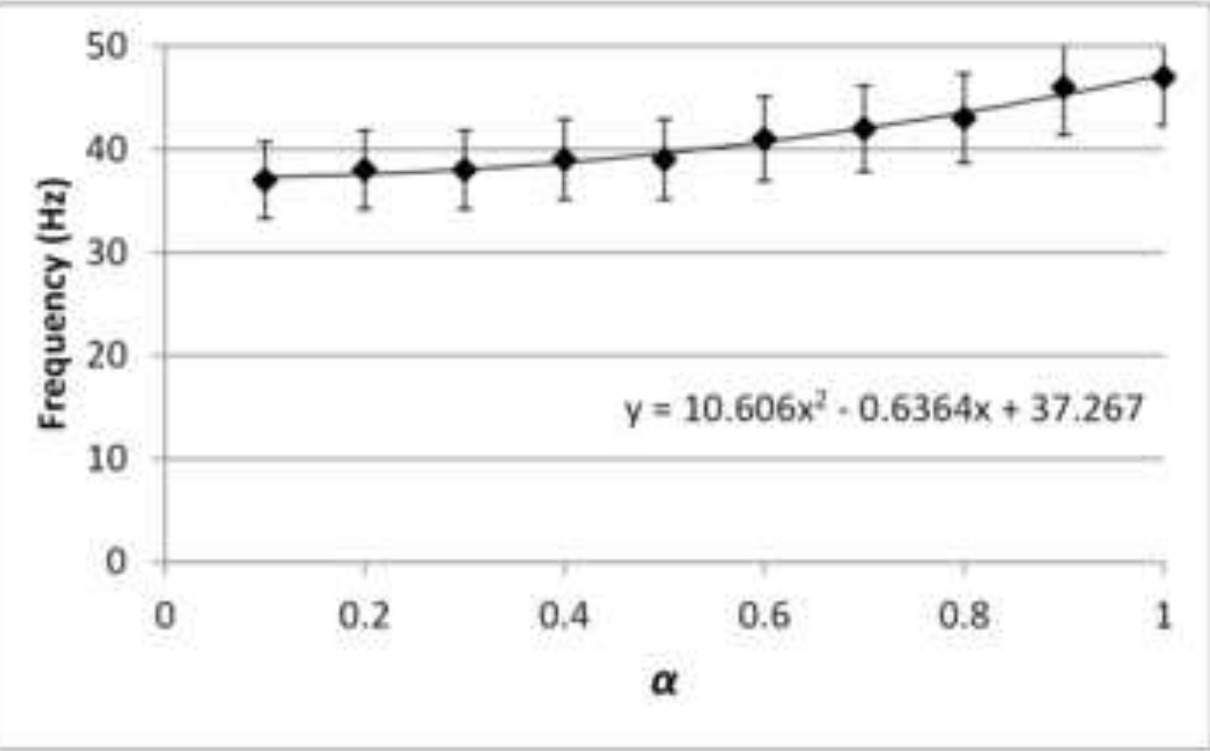

b)

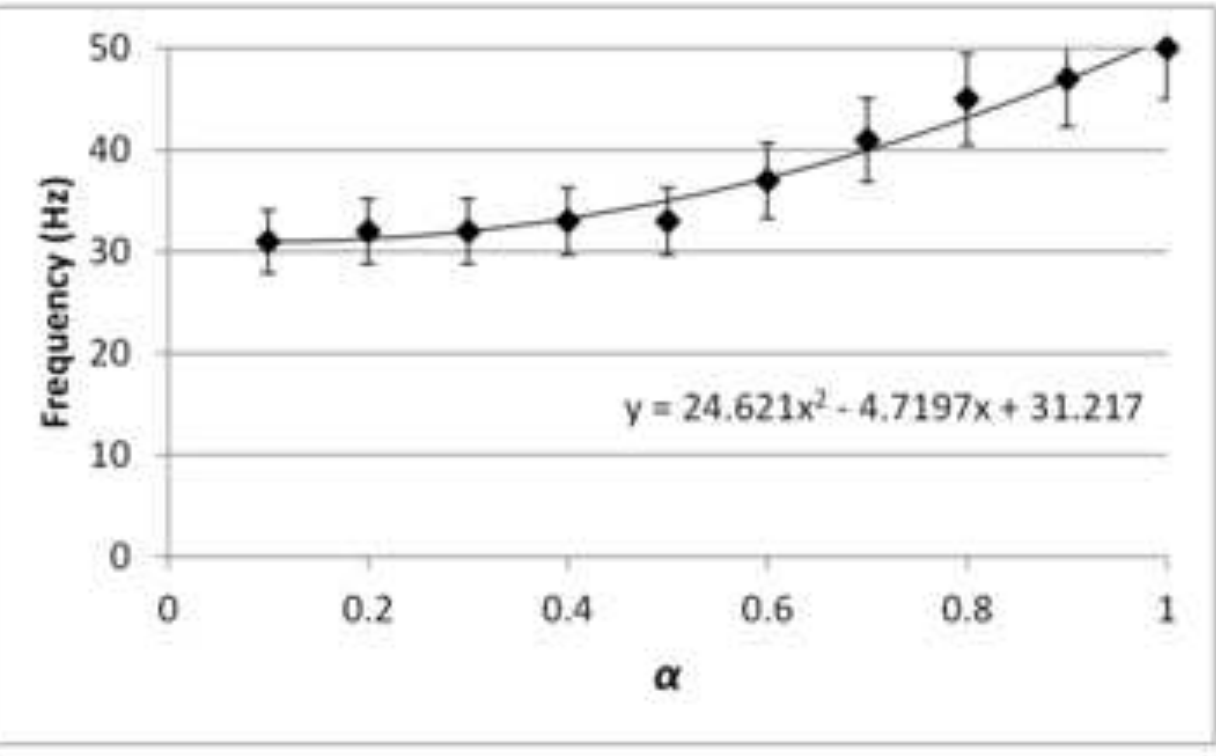

d) 
Click here to download high resolution image

a)

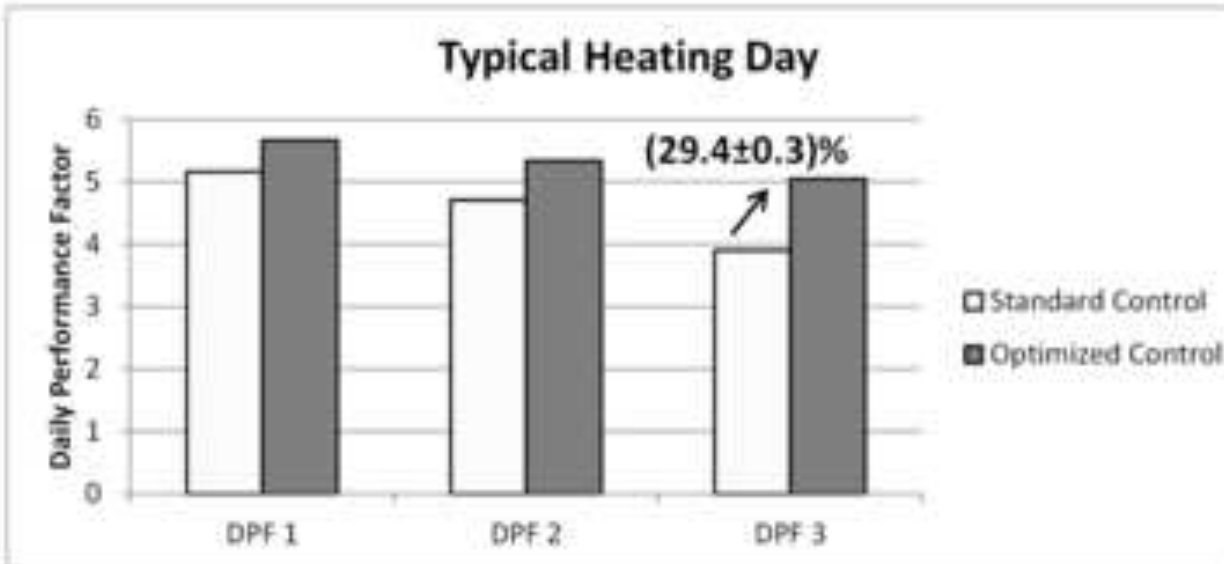

b)

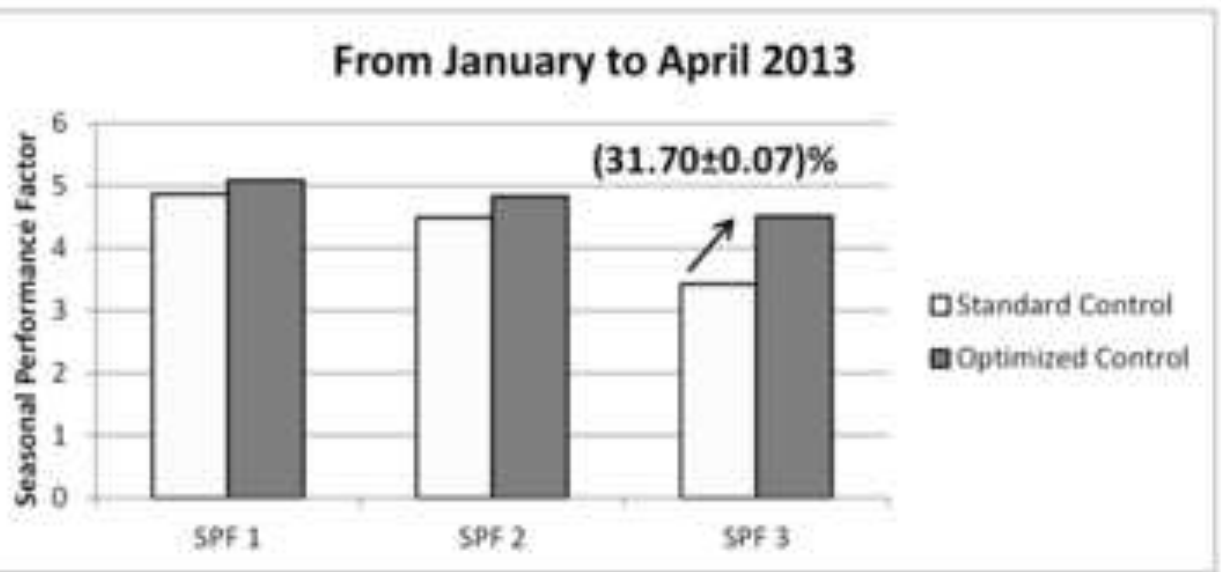

